\title{
Técnicas de envilecimiento: Una reflexión desde el pensamiento de Gabriel Marcel
}

\author{
Debasement Techniques: \\ Reflecting from Gabriel Marcel's Thought
}

\author{
José Joaquín Castellón-Martín \\ Facultad de Teología San Isidoro de Sevilla \\ Sevilla, España \\ jcastellonm64@gmail.com \\ ID ORCID 0000-0003-4813-0763
}

\begin{abstract}
Resumen: Este artículo es una reflexión de la crítica de Gabriel Marcel sobre la tecnología; proponiendo las líneas de fuerza de su pensamiento, poniéndolas en el contexto en el que fue escrita. Continúa la reflexión de Marcel aplicando sus intuiciones a la situación de nuestro mundo tecnificado, especialmente en lo que se refiere a las redes sociales. Es una introducción viva al pensamiento del autor francés no desde un punto de vista sistemático, sino desde el diálogo con su pensamiento.
\end{abstract}

Palabras claves: Gabriel Marcel, técnica, manipulación, redes sociales.

\begin{abstract}
The following article offers a reflection on Gabriel Marcel's critique on technology. The force lines of his thought are presented by putting them in the context in which they were written. It continues Marcel's reflection by applying his intuitions to the situation of our technified world, especially in the subject of social networks. It is a deep introduction to the French author not from a systematic point of view but in a form of a dialogue with his thoughts.
\end{abstract}

Keywords: Gabriel Marcel, technology, manipulation, social networks.

\section{INTRODUCCIÓN: HORIZONTE REFLEXIVO DE MARCEL}

La pertinencia y actualidad de una reflexión sobre el envilecimiento personal, social y político creo que, por desgracia, está fuera de dudas. decía:

El propio Marcel intuía la cualidad profética de sus palabras cuando

las indicaciones que hoy he pretendido aportar van destinadas a orientar una indagación que verse sobre las condiciones que están sin duda llamadas 
a prevalecer en un mundo entregado cada vez más completamente a las técnicas. ${ }^{1}$

La sociedad actual está estructurada por la tecnología. Vivimos en un mundo donde la producción, las relaciones, el pensamiento y la propia vida están mediados tecnológicamente. La producción industrial está mediatizada por una tecnología cada vez más especializada. Las relaciones personales han cambiado drásticamente por los nuevos medios que ofrece la tecnología con un horizonte inimaginable de posibilidades, también de manipulación. Los propios conceptos con los que pensamos se van tiñendo cada vez más de mentalidad tecnológica. Por eso, una reflexión sobre la tecnología y su influencia en nuestra humanidad es radicalmente pertinente; máxime cuando el inmenso poder de la técnica, independiente de una verdadera racionalidad humana, parece controlar hoy nuestro mundo.

"La técnica se presenta como el conjunto de medios sistematizados que permiten al hombre subordinar a sus fines una naturaleza tratada como ciega o incluso rebelde". ${ }^{2}$ Esta capacidad del hombre aparece como algo digno de admiración, como una proeza que llena de asombro. Nos hace descubrir el inmenso poder de la inteligencia humana. Pero, pasado ese asombro, nos devuelve una naturaleza y una realidad"domesticada", que ha perdido su belleza y su misterio, que se ve reducida a las contingentes necesidades y los fines a corto plazo de los humanos. La realidad ya no sigue su curso espontáneo, su dinamismo intrínseco que nos pone en relación directa con lo que nos supera y nos trasciende. La técnica reduce la realidad a la medida de las necesidades concretas y coyunturales de las personas, tal y como se definen por conveniencia, utilidad o comodidad en la cultura vigente, cosa que no siempre responde a lo que nuestra realidad personal reclama.

Muchos autores se han caracterizado por críticas a la creación de un mundo desnaturalizadamente técnico. Comenzando por Platón

1 Nuestra reflexión estará centrada en el texto "Técnicas de envilecimiento", capítulo del libro Gabriel Marcel, Los hombres contra lo humano, Madrid, Caparrós Editores, 2001, 41-64; edición francesa: Les hommes contre Ihumain, La Colombe, Paris 1951; aunque necesitaremos acudir a otros escritos del autor para completar su análisis.

2 MARCEL, Los hombres contra lo humano, 126. 
y la tradición clásica, ${ }^{3}$ y siguiendo por Marx, Heidegger, ${ }^{4}$ la escuela de Frankfurt, ${ }^{5}$ la corriente del Ecologismo y el Comunitarismo a finales del siglo $X X_{1}^{6}$ han criticado la deriva hacia una razón disminuida de una racionalidad tecnológica pretendidamente autosuficiente. Después de unos siglos en los que el paradigma epistemológico prevalente estaba centrado en la razón categorial de las ciencias empíricas, marcando incluso el estudio de la historia y de la persona, la reacción ante este reduccionismo vino desde muy diversos frentes.

La aportación de Marcel a esta corriente es especialmente incisiva y original por varias razones. Primero, su reflexión sobre la incidencia de la técnica en nuestra manera de vivir la humanidad parte de un contexto reflexivo muy concreto y significativo: la deshumanización programada y llevada a cabo con técnicas precisas en los campos de concentración del régimen nazi; una deshumanización que afectaba tanto a las víctimas como a los verdugos de aquel régimen. Así pues, Marcel no reflexiona desde la perspectiva de una esencia de lo técnico en abstracto, ni siquiera de las consecuencias éticas de la tecnocracia desde un punto de vista general con pretensiones de explicación total. Su reflexión tiene, más bien, la virtualidad de afrontar desde lo concreto histórico cómo la técnica ha servido para que unos seres humanos envilecidos trataran de envilecer a otros seres humanos; es decir, busca la explicación racional, las condiciones de posibilidad de un hecho histórico que, por desgracia, no ha sido aislado.

Ya el título del artículo de Marcel, "Técnicas de envilecimiento", es significativo; el objeto y el sujeto del envilecimiento de la técnica quedan en suspenso. En principio toda técnica requiere un técnico; es decir, alguien que tras ella la conduce, la usa, la utiliza con un fin previsto; con otras palabras, una conciencia racional y responsable de sus actos que dirija el proceso técnico. Pero estas reflexiones no nos hablan solo del sujeto que usando unas técnicas concretas envilece a la sociedad. El proceso de envilecimiento social es, en muchas ocasiones, anónimo, impersonal, en el que todos son víctimas; también el victimario sufre las consecuencias de su propia actuación, y se ve sometido por sus propias técnicas de

3 Cf. su elogio a la vida sencilla en Platón, República. Barcelona, Espasa libros, 2011, vol. II, 371E-372D.

4 Cf. Martin Heidegger, La pregunta por la técnica, en Filosofía, Ciencia, Técnica. Edición del profesor Jorge Acevedo, traducción de Francisco Soler, Santiago de Chile, Ed. Universitaria, 1997.

5 Cf. Herbert Marcuse, El hombre unidimensional, Barcelona, Planeta, 2016.

6 Cf. la crítica al utilitarismo de Alasdair MacIntrre, Tras la Virtud, Barcelona, Planeta, 2013. 
envilecimiento. En el acto de envilecer a los demás se envilece a sí mismo primero. Esas técnicas tienen siempre un sujeto a-personal, no-racional, un sujeto que es un no-sujeto, que ha renunciado a lo más profundo de lo que subyace en su ser.

El título nos sitúa también en el horizonte de la crítica social. Envilecer es deformar lo que tiene forma propia, desfigurar lo que aparece bello en sí mismo, hacer degenerar lo que puede asumir un dinamismo de perfección. Toda crítica social supone un horizonte axiológico que permite enjuiciar la sociedad; unos valores de los que se aparta quien envilece o de los es apartado aquel que es envilecido. Afirmar la realidad del envilecimiento es afirmar de manera rotunda la vigencia de unos valores, como quiera que se entiendan estos, que han de guiar la vida de las personas, la denuncia de la pérdida o la corrupción de los dinamismos que permiten el pleno desarrollo de la realidad personal.

Desde muy joven, Marcel, como lo señala él mismo, estuvo sensibilizado con los problemas de la injusticia y la discriminación: "Siendo niño quedé muy impresionado por el caso Dreyfus; creo poder decir que este acontecimiento marcó en mí una cierta actitud". ${ }^{7}$ Este caso marcó en él una actitud crítica respecto a la invisibilidad de la discriminación y la negación de facto de la entera dignidad de personas a algunos hombres y mujeres.

Este proceso de negar la dignidad humana a una persona o a un grupo de personas tiene un origen oscuro e inaccesible, como todo concepto elaborado por nuestra mente: “Un arte oculto en las profundidades del alma humana, el secreto de cuyos mecanismos difícilmente podremos arrancar a la naturaleza, poniéndolo al descubierto ante nuestros ojos" ${ }^{8}{ }^{8}$ En nuestra sociedad actual la propaganda, la publicidad, los medios de comunicación de masas, siempre en manos de grandes corporaciones financieras y sus informativos, van generando unos mecanismos desde los cuales interpretamos nuestra realidad y que son, como dice Kant,

7 Cf. Gabriel Marcel - Paul Ricceur, Entretiens Paul Ricœur-Gabriel Marcel. Paris, Aubier, 1968, 96-98; citado por José SECo PéreZ, Introducción al pensamiento de Gabriel Marcel. Madrid, Ediciones del Instituto Enmanuel Mounier, 1990, 10. El caso Dreyfus fue el proceso de acusación y condena del capitán del ejército francés Alfred Dreyfus por espiar en favor de Alemania, con pruebas falsificadas por los propios altos mandos del ejército francés. La condición de judío del capitán Dreyfus dio alas a una acusación basada en pruebas muy débiles. Este caso puso de manifiesto la tensión antisemita de una parte importante de la sociedad francesa, sus dirigentes y agentes sociales.

8 Max Horkheimer, Teoría Crítica, Buenos Aires, Amorrortu, 2003, 235; citando la sección "Sobre el esquematismo de los conceptos puros del entendimiento" de la Crítica de la Razón Pura. 
muy difíciles de poner al descubierto ante nuestros ojos. Mientras más medios técnicos tenemos, de más medios "disponen hoy todos los charlatanes para imponer su amodorradora mercadería a los papanatas". 9 Pero una "mercadería" con la que pensamos y enjuiciamos la realidad y a las personas.

El contexto de la Francia de después de la Segunda Guerra Mundial, en el que se escriben estas palabras, nos ofrece la perspectiva necesaria para acceder a su sentido. Dos situaciones concretas hemos de tener en cuenta para encontrar su sentido histórico-crítico.

En primer lugar, Francia era un país que se avergonzaba por su actitud ante la invasión alemana ${ }^{10}$ y por la impunidad con la que los judíos habían sido deportados en el régimen de Vichy, hacía solo unos cuantos años; un país en el que los colaboracionistas con el régimen nazi no habían sido una excepción, sino una vergonzante cotidianeidad; un país que se hizo el distraído ante la violación de su soberanía y la violación estremecedora de los derechos humanos: campos de concentración como Rivesaltes, desde donde judíos, gitanos y republicanos españoles eran enviados a los campos de exterminio nazi. Este ensayo sobre las técnicas del envilecimiento tiene como trasfondo el envilecimiento que la sociedad francesa había vivido solo una década antes.

En segundo lugar, otra situación que contextualiza la reflexión de Marcel es la justificación del colonialismo y de la ocupación de explotación económica de Siria, Argelia y Vietnam, así como de otros territorios. La sociedad francesa vivía una doble moral, desde la democracia cristiana hasta los comunistas, por la que no se tomaba en consideración la contradicción de salir del yugo de la opresión de un país extraño y seguir oprimiendo a otros países por el sentimiento de una "grandeza francesa" mal entendida. Eso era posible porque se había "perdido en el sentido más profundo la conciencia de sí mismo" ${ }^{11}$ Siendo el país de los derechos humanos y creyéndose la cuna de la democracia, la pretensión de gran parte de la clase política francesa de continuar con un proyecto colonizador manifiesta una confusión enorme que, por estar contra lo mejor de su propia historia, puede llamarse envilecimiento.

El hombre, sentencia Marcel, sumido en el horizonte de problemas del tener y obsesionado por el progreso acumulativo de la técnica, pierde "las regulaciones trascendentes que le permiten orientar su conducta e

\footnotetext{
9 MARCEL, Los hombres contra lo humano, 62.

10 Cf. La reciente novela de Pierre Lemartre, El espejo de nuestras penas, Madrid, Salamandra, 2020; donde describe la situación de debacle y pánico de todo el pueblo francés ante la invasión nazi.

11 MARCEL, Los hombres contra lo humano, 64.
} 
identificar sus intenciones; se halla cada vez más inerme ante las potencias destructoras desencadenadas en torno a él y ante las complicidades que estas encuentran en el fondo de él mismo".${ }^{12}$ Para Marcel, esta pérdida de regulaciones trascendentes está a la base de la degeneración de la sociedad europea de su tiempo. Por eso, a pesar del enorme prestigio de Sartre en el panorama francés de la época, se atreve a denunciar que el existencialismo nihilista está también a la base de estos comportamientos envilecidos, sin valores. El nihilismo, en coherencia consigo mismo, ni siquiera puede calificar de envilecida a la deshumanización de las actitudes cobardes, racistas o colonialistas. Podemos tener conciencia del envilecimiento de nuestra sociedad solo si postulamos unos valores por los que cada persona se respeta a sí misma, y no una nada abismal como horizonte de la vida personal. Nihilismo y tecnocracia están en el punto de mira de esta reflexión, ya que Marcel considera que son las dos condiciones que, retroalimentándose, están haciendo posible la construcción de un mundo deshumanizado, donde la persona llega a ser un trampantojo para sí misma.

\section{EL MÉTODO FILOSÓFICO DE LA REMEMORACIÓN CRÍTICA Y CREATIVA}

En línea con la fenomenología, pero separándose conscientemente de ella, Marcel busca descubrir el pálpito fundamental de la vida, la verdadera profundidad de lo humano, sin reducirlo a las categorías que la ciencia abstrae de lo real, dejando fuera todo lo que sale de su previa definición o de sus conclusiones. Frente al espíritu metódico y sistemático de la escuela fenomenológica, Marcel asume como método una profundización que busca, por encima de cualquier sistema, las luces que nos permitan comprendernos y comprender nuestra sociedad. La falta de sistema no es una característica buscada, pero Marcel huye de que el sistema coarte la potencia de la inteligencia para analizar la vida tal y como se nos muestra. Podríamos decir que, más que un análisis de lo vivido, busca hacer rememoración crítica, buscando los dinamismos esenciales de la propia humanidad. Por eso, en otro momento apunta: "Yo no soy existencialista, a pesar de lo que se ha dicho y escrito sobre mí. Yo soy más bien un neo-socrático. Mi pensamiento es interrogativo, como mi teatro" ${ }^{13} Y$ es que, para él, la literatura es otra forma de acceder a la profundidad de lo humano que abre caminos para la reflexión

12 MarCel, Los hombres contra lo humano, 64.

13 Entrevista recogida en V. Heria, Viajes al centro de la tierra. Madrid, Plaza y Janés, 1976, 29. 
filosófica. Marcel se comprende como filósofo-poeta que busca descubrir desde la razón creativa el alma de los acontecimientos. La reflexión de Marcel, por intentar acceder a la profundidad de la persona, abre problemas y se asoma a verdades fundantes, metafísicas. Y, a pesar de que el tema propuesto sea el de la manipulación mediática en la sociedad occidental, sus reflexiones desbordan lo meramente sociológico. Así es dicho explícitamente:

Nunca será excesiva la fuerza con que declaremos que la crisis que está hoy atravesando el hombre occidental es una crisis metafísica; probablemente no exista peor quimera que la de imaginarse que este o aquel ajuste social o institucional podría bastar para apaciguar una inquietud que procede de lo más hondo del ser. ${ }^{14}$

Marcel no quiere que su reflexión metafísica derive en una abstracción que sea olvido de lo vivido. La ciencia histórica — piensa — parte del espíritu de abstracción propio de las ciencias categoriales, se convierte, muchas veces, en "una manera de olvidar o, si se prefiere, de perder el contacto real con el acontecimiento, a falta de lo cual este queda reducido a mera mención abstracta. [Así] cuando el pasado solo es conocido históricamente se acumula fuera de la vida" ${ }^{15}$ La historia con pretensiones de ciencia tiene la tendencia de dejar escapar lo fundamental del pasado a fuer de precauciones objetivas y metódicas. Gabriel Marcel quiere ampliar el concepto de experiencia que tiene el pensamiento objetivista y unívoco; apela a una experiencia en la que la persona se encuentra con realidades profundas y significativas. Sin tener la obsesión de la demostrabilidad, señala que podemos tener experiencia de lo irreductible. ${ }^{16}$ Este método de rememoración crítica y de profundidad de lo vivido, permite al filósofo no salirse de la realidad, evitando que la filosofía sea, como tantas veces, un ejercicio del espíritu de abstracción, que solo consigue obras conceptuales "de museo", sin ayudarnos a vivir crítica y lúcidamente la realidad.

La realidad personal necesita un método propio porque la persona, y su ámbito de realidad, no es un objeto más del mundo del que el filósofo pueda ser mero espectador. Todo lo humano afecta al filósofo personalmente y ha de ser analizado personalmente, es decir, creativamente. Para Marcel solo el ser humano"es" realmente, porque solo el ser humano puede ser creativo: "Desde el momento en que hay creación,

14 Marcel, Los hombres contra lo humano, 41.

15 MARCEL, Los hombres contra lo humano, 42.

16 Como apunta Feliciano Blázquez Carmona, La filosofía de Gabriel Marcel, Madrid, Encuentro, 1992. 
sea del grado que sea, estamos en el ser" ${ }^{17}$ Cuando la persona r enuncia a la creatividad en su vida se desliza por la pendiente del no ser, del no sentido, de lo sin vida. La verdadera comprensión de la realidad exige del filósofo y de cada persona una reelaboración creativa desde las propias experiencias de lo analizado; de tal manera que la comprensión de lo acontecido se convierta en un nuevo acontecimiento que nos hace caminar como personas.

\section{TÉCNICAS DE COSIFICACIÓN DEL OTRO: REMEMORACIÓN DE LOS CAMPOS DE CONCENTRACIÓN}

Marcel apunta en el inicio del artículo una definición del concepto "técnica de envilecimiento" para enmarcar la reflexión. Esta definición no señala límites de la investigación, sino una dirección en la que profundizar en el recuerdo analítico, crítico y revelador que propone:

Entiendo por técnicas de envilecimiento el conjunto de procedimientos llevados a cabo deliberadamente para atacar y destruir, en individuos que pertenecen a una categoría determinada, el respeto que de sí mismos pueden tener y, ello, a fin de transformarlos poco a poco en un desecho que se aprehende a sí mismo como tal y al que, a fin de cuentas, no le queda sino desesperar de sí mismo, no solo intelectualmente, sino vitalmente. ${ }^{18}$

El envilecimiento no es mero trato deshumanizado que no respeta la dignidad de la persona. Busca que esta desespere de esa dignidad intrínseca que le es propia y que olvide y abandone su propio ser. Envilecer conlleva destruir a la persona en lo que esta tiene de tal, en lo que tiene de ser espiritual. Esta definición se inspira en los métodos de deshumanización empleados por los nazis con los judíos, y llevados al extremo en los campos de concentración nazis. Los testimonios de personas que habían sido sometidas a la tortura del régimen de esos campos así lo apuntan: "Intentaban envilecernos por todos los medios. Explotaban todas las cobardías, excitaban todas las envidias y suscitaban todos los odios. Era necesario esforzarse día a día para conservar la propia integridad moral. El barniz civilizado se pulveriza con rapidez" ${ }^{\prime 19}$, decía una superviviente. La elección de los encargados de los prisioneros entre lo peor de la sociedad, la manera de disponer las letrinas, de envenenar las relaciones humanas suscitando envidias y rencores... En todo esto, las

17 Cf. Gabriel Marcel, Segundo Diario Metafísico, Buenos Aires, Losada, 1956, anotación del 13-X-1933.

18 MARCEL, Los hombres contra lo humano, 44.

19 Ibidem. 
víctimas veían la voluntad de humillar, de deshumanizar, de minar la autoestima de los presos, la conciencia de su propia dignidad. El objetivo era claro: "era preciso que quien efectivamente no vale nada reconozca su propia nada, sin que baste con que la perciba intelectualmente. [Se] instaura como principio que el otro ya era virtualmente el ser desechable que efectivamente ha acabado siendo, y que, por ende, era justo tratarlo con un rigor extremo". ${ }^{20}$

Esta dinámica de destrucción de la humanidad es también apuntada por Hannah Arendt en su análisis de los totalitarismos del siglo $X X$. Con respecto a la política del régimen nazi con los judíos comenta que la enajenación de la dignidad de persona comienza mucho antes del confinamiento en el campo de concentración. "Los nazis comenzaron su exterminio de los judíos privándoles de todo status legal (el status de ciudadanía de segunda clase) y aislándolos del mundo de los vivos mediante su hacinamiento en guetos" ${ }^{21}$ Se los trataba como no-personas, para que llegaran a serlo. Una primera condición para poder despersonalizar a alguien es cortar todas sus relaciones personales, dejar su condición humana tan desnuda de apoyatura social que se redujera a mera abstracción, sin ciudadanía, sin contacto con otros grupos sociales, su dignidad es absolutamente vulnerable. ${ }^{22} \mathrm{El}$ fin perseguido consiste en hacer perder a las personas la conciencia de su propia dignidad, hasta llegar a que se consideren a sí mismas como un engranaje prescindible de un mecanismo impersonal a quien le deben sometimiento objetivo, intelectual y sentimental.

Ese mismo envilecimiento afecta tanto a las víctimas como a los torturadores y a los que, con su silencio, por indiferencia o miedo, niegan implícitamente su propia dignidad al negársela explícitamente a otras personas. La irresponsabilidad de los"obedecedores solamente de órdenes, los asemeja a instrumentos inocentes de un inhumano e impersonal curso de acontecimientos". ${ }^{23}$

Arendt apunta algo que también estará presente en el análisis de Marcel: que la dinámica del miedo y la de la propaganda en el régimen nazi están en una misma línea y se usan para conseguir los mismos objetivos. Apunta así a una íntima conexión de ambos procesos desde la despersonalización que provocan; ambos, por distintos caminos, consiguen disminuir el ámbito de lo personal, de lo voluntario y consciente.

\footnotetext{
20 MARCEL, Los hombres contra lo humano, 47.

21 Hannah ARENDT, Los orígenes del totalitarismo, Madrid, Taurus, 1998, 247.

22 Arendt habla de "la abstracta desnudez de ser nada más que humanos", que era de manera real"su mayor peligro": ibid., 250.

23 ARENDT, Los orígenes, 24.
} 
La propaganda nos hace vivir en una pseudo-realidad, y todos nuestros pensamientos son como la imagen de los espejos deformantes. Cuando otros manipulan nuestra conciencia, nos impiden hacernos cargo de la realidad y desencadenan procesos de deshumanización. Así mismo, el terror nos deshumaniza y afecta a nuestra conciencia, aunque por otros caminos. El terror mina fundamentalmente nuestra voluntad, hace que solo atendamos al impulso más básico de cualquier ser vivo, el instinto de supervivencia; y cualquier otra consideración se ve oscurecida y postergada. La propaganda deforma la realidad, el terror la entenebrece:

La propaganda es, desde luego, parte inevitable de la"guerra psicológica", pero el terror lo es más. El terror sigue siendo utilizado por los regímenes totalitarios incluso cuando ya han sido logrados sus objetivos psicológicos: su verdadero horror estriba en que reina sobre una población completamente sometida. Allí donde es llevado a la perfección el dominio del terror, como en los campos de concentración, la propaganda desaparece por completo. ${ }^{24}$

Tanto la propaganda como el terror persiguen anular la capacidad de pensar críticamente. Es esta capacidad de pensamiento crítico lo que más preocupa al régimen totalitario. Por eso, para estos regímenes, todos los ciudadanos son sospechosos por definición, simplemente por su capacidad de pensar. Todos son objeto de propaganda y de terror.

La reflexión por la que Marcel nos ha guiado no consiste en explicar cómo la técnica en general afecta a la persona, sino cómo las técnicas de envilecimiento, rememoradas en los campos de exterminio, están presentes en su sociedad. Pero esa mirada a lo más oscuro y tenebroso del ámbito de la técnica nos puede desvelar los procesos que la tecnología imprimen en nuestra sociedad y en nuestra realidad sin que nos percatemos.

El objetivo final de los campos de concentración ha sido anular la dignidad del otro, tanto de su propia conciencia de dignidad como de la que los demás pudieran reconocerle. Reducido a cosa no tenía derecho ni a tener derechos, en expresión de Arendt. Por desgracia, las técnicas por las que se desposee al otro de su rostro humano no faltan en nuestra sociedad. Es más, podríamos decir que se han generalizado en muchos ámbitos. Esta generalización se ve hoy día en la confrontación política radicalizada y polarizada, en la criminalización y conversión en una caricatura humana del adversario, en la degradación televisiva de los "realities", en los que las audiencias se disparan cuando hay un concursante humillado, maltratado y que asume las humillaciones como si las

24. ARENDT, Los orígenes, 281. 
mereciera; en la disputa sucia de los debates mediáticos, en los que unos tertulianos se ensañan con las debilidades de los otros; en las injustas generalizaciones, que rayan el racismo, por las que se criminaliza a un colectivo, identificando a todos sus miembros con el vicio o crimen de algunos. Los errores o delitos de mujeres, hombres, negros, izquierdistas, derechistas, latinos, gitanos, políticos o sacerdotes, sirven de excusa para rebajar su condición de persona y convertirlos en grupos a los que se les insulta y se les priva de sus derechos impunemente.

Este proceso es"infinitamente más peligroso"si la propaganda de cosificación del otro es asumida por el Estado; "allí donde el mismo Estado tiende a comportase como partido, desde esta perspectiva, aparece con la mayor claridad el parentesco existente entre la propaganda y las técnicas de envilecimiento". ${ }^{25}$ "La dictadura es el gobierno de la opinión", en tanto la opinión de las masas, debidamente manipulada, se convierte en el mayor soporte de su poder. "La opinión, por cuanto pertenece al dominio del «se» impersonal, por cuanto en realidad flota entre las conciencias como un pesado vapor, es en sí misma algo bastante vil"26; y sin embargo tiene el poder de la fuerza bruta, de la masa, del peso inerte que impide moverse. Por ello, también puede decirse que el gobierno desde la opinión, la mercadotecnia o el"marketing", es una dictadura. Cuando no importa la justicia de lo que se hace o lo ajustado de las normas que se toman, sino cómo vender un producto ideológico-político en el mercado de la opinión, estamos muy cerca objetivamente de la mentalidad dictatorial. En nuestras sociedades occidentales, estamos precisamente en algo que se parece mucho al gobierno de la opinión. Las tendencias populistas son el cuerpo que está tomando el poder de la opinión en nuestros sistemas políticos. Populismo, sectarismo y cosificación del adversario van de la mano en el proceso que está envileciendo nuestro tejido social. El análisis de Marcel sigue sorprendiendo por su actualidad: "Salta a la vista - dice- que entre pasiones sectarias y propaganda existe una solidaridad recíproca que linda con el círculo vicioso". ${ }^{27}$

\section{EL DOBLE ROSTRO DE LA TÉCNICA}

Partiendo del análisis de este aspecto de la técnica no es difícil comprender que la reflexión de Marcel remarca más las sombras que las luces. Sin embargo, nuestro autor no deja de tener en cuenta que la tecnología es fruto de la capacidad racional del hombre, fruto de su intuición creativa

\footnotetext{
25 MARCEL, Los hombres contra lo humano, 50.

26 MARCEL, Los hombres contra lo humano, 51.

27 MARCeL, Los hombres contra lo humano, 63.
} 
y, por tanto, también un signo de su humanidad. Pero cuando la técnica asume un desarrollo tan grande que desborda la capacidad de las personas de usarla y, al contrario, son las propias personas las que son usadas por instancias que se rigen por la lógica de la tecnología, la valoración es diversa. "La técnica — dice Marcel- envilece no en sí misma, no cuando cumple su función de medio, sino cuando reivindican una suerte de primacía con respecto a un pensamiento que se concentra en el ser, y no en el hacer". ${ }^{28}$

Marcel, como Ortega, Heidegger y todos los filósofos que han reflexionado sobre la tecnología, ven en ella dos rostros: un rostro que la muestra como hija de la creatividad racional de la persona, y otro que nos la desvela como madre de engendros deshumanizados y lleva a la humanidad al borde del abismo. No hace falta acudir a la filosofía de los últimos siglos para ver descrito este rostro siniestro de la técnica. En los primeros capítulos del primer libro de la Biblia, en forma de narración de pecado original, se nos regala el mito-narración de la Torre de Babel, en el que se relata cómo la humanidad pretende ponerse por encima de la voluntad de Dios usando su saber tecnológico. El relato bíblico es sarcástico cuando comenta que Dios se percató de lo que la humanidad estaba haciendo cuando miró hacia debajo de donde Él estaba: "Bajó Yahveh a ver la ciudad y la torre que habían edificado los humanos" (Gen 11,5). Por más alto que los hombres puedan subir, nunca llegarán ni al estrado donde el Dios altísimo reposa sus pies, y todo lo que el orgullo construye queda reducido a escombros. La tecnología se muestra en la Biblia desde el orgullo humano, desde su afán por sobreponerse a la naturaleza que Dios ha creado, por sobreponerse a la propia voluntad de Dios. La tecnología se intuye como un poder tentado, pareciera que esencialmente, de emanciparse de la dependencia de Dios. Este texto tiene, además, una lectura que no es teologal-antropológica, sino socio-económica, que no suele hacer la exégesis bíblica, y que solo los albañiles que se suben en andamios hacen inmediatamente: ¿Cuántos niveles de andamios tienen que subirse para llegar por encima de las nubes?, ¿cuántos obreros tendrían que morir para hacer una torre que subiera a esa altura?, ¿cuánto sacrificio y sudor de la gente más sencilla que sin entender aquel proyecto perdería su vida en él? Los proyectos técnicos megalómanos siempre arrasan con la vida de los más pobres. Lo mismo que el Dios Jano, la técnica tiene un doble rostro. Pero no lo interpretemos como decía la mitología latina, uno que mira al pasado y otro que mira al futuro; sino como lo interpretó Albert Camus, al que Marcel tenía gran aprecio, y

28 MARCEL, Los hombres contra lo humano, 61. 
para quien esta deidad romana era signo de una personalidad radicalmente vacía por vivir en la superficie contradictoria de estar meramente centrado en sí misma. ${ }^{29}$

\section{LA TÉCNICA Y EL ENVILECIMIENTO DEL SER ESPIRITUAL}

La postura de Marcel podría caracterizarse como radical:"Todo progreso técnico comporta, para quien se beneficia de él sin haber participado en el esfuerzo de conquista cuyo coronamiento es ese progreso, un gravoso tributo que precisamente se traduce en un determinado envilecimiento del ser espiritual" ${ }^{30}$ La técnica es fruto de la creatividad de la persona, pero cuando se asume sin que ese esfuerzo creativo se mantenga, en vez de recrearnos, nos acomoda, en vez de desarrollar nuestro espíritu, lo adormece. "No sería excesivo decir que cuanto más domina el hombre en general la naturaleza, más esclavo de esa misma conquista es de hecho el hombre en particular". ${ }^{31}$

El adocenamiento tecnológico de la sociedad actual, y hemos de tener en cuenta que la época desde la que Marcel habla no es la nuestra, tiene como primera consecuencia la confusión de la felicidad con el confort. La persona rodeada de terminales tecnológicos está expuesta a la tentación constante de estar entretenida sin profundizar en nada, de vivirlo todo desde la superficialidad del mero espectador. "La técnica se presenta, entre quienes toda vida interior es demasiado a menudo cegada, como el medio infalible de alcanzar un confort generalizado fuera del cual no son capaces de concebir la felicidad". ${ }^{32}$ No hay época en la historia sin técnica; el homo sapiens es siempre homo faber; pero el uso de las técnicas, que nuestra época nos permite, ha de venir acompañado por un esfuerzo personal en cómo y para qué usamos las posibilidades que nos brindan. Sin ese esfuerzo las técnicas, de manera especial las comunicativas, se erigen en controladoras de nuestro pensamiento. Es más, van sustituyendo nuestra propia actividad de pensar. Marcel ve con claridad el peligro de que construyamos una cultura en la que la vida interior y nuestra vida intelectual sean cegadas por saturación irreflexiva. "Una civilización en la que se puede decir que resulta finalmente recusada toda posibilidad de contemplación, se encamina inevitablemente hacia una filosofía que mejor valdría calificar de misosofía" ${ }^{33}$ Las técni-

\footnotetext{
29 Cf. Albert CAmus, La caída. Buenos Aires, Losada, 1957, 43.

30 MarCel, Los hombres contra lo humano, 52.

31 MARCEL, Los hombres contra lo humano, 53.

32 MARCEL, Los hombres contra lo humano, 54.

33 MARCEL, Los hombres contra lo humano, 58.
} 
cas de la comunicación se imponen a nuestra conciencia de tal manera, tanto por el poder de la sugestión de las imágenes y el sonido, como por la reiteración y la extensión con que se consumen, que imposibilitan un pensamiento de profundidad que se cuestione qué es lo que ocurre en el fondo de la realidad y de nuestra realidad. Cuando el pensamiento consiste en repetir lo que de otros escuchamos, y en valorar nuestra vida desde espejismos mediáticos ya elaborados, ya no merece tal nombre.

Marcel señala cómo la tecnología parece que se ha convertido en la salvación de la humanidad en cualquiera de sus desdichas. Parafraseando al profesor Sanmartín podríamos decir que los ingenieros se han erigido en los nuevos redentores de nuestra sociedad. ${ }^{34}$ La técnica se ha transmutado en una nueva clase de idolatría: "Podría decirse simplemente que el progreso técnico expone al hombre al peligro de la idolatría. El hombre no se percata de ello porque se hace de la idolatría una imagen infantil de cuyo engaño es víctima; la idolatría consiste, a sus ojos, en adorar pequeños fetiches grotescos". ${ }^{35}$ Las nuevas técnicas y los ídolos de las religiones primitivas parecen muy lejanos entre sí, pero, en ambos, a las creaciones del propio hombre se les atribuyen poderes por encima de lo humano; unos poderes que pareciera que permitirían encontrar la panacea a todos los problemas, tanto de índole económica, como psíquica o espiritual. Todo parece poder solucionarse si se encuentra la técnica apropiada para tratarlo. Pero lo más terrible es que la fe ciega en la técnica exige, como aquellos ídolos primitivos, sacrificios humanos o incluso el sacrificio de nuestra humanidad.

Cuando los medios se enarbolan como fin, y la técnica decide el camino y el horizonte hacia el que caminar, el fin se reduce a su más pobre apariencia. La técnica se ha elevado de tal manera en nuestra cultura que su propia mención lo justifica y lo avala todo, hasta lo más trivial o absurdo. La verdadera finalidad de la vida se oscurece ante los focos de la luz artificial, el bien se reduce a lo que la técnica tiene a su alcance, que no es ni puede ser ni la espiritualidad ni la comunión personal. La técnica acaba sacrificando nuestra propia humanidad ante sus criterios a-humanos

34 Una reflexión ya clásica en la filosofía española sobre la técnica es la de José SANMARTín, Los nuevos redentores. Barcelona, Anthropos, 1987. La reflexión del profesor Sanmartín analiza críticamente cómo la técnica se ha convertido, tanto en la ciencia como en la sociedad, en la excusa perfecta para no profundizar en la realidad. Los técnicos, nuevos redentores, ya saben qué es lo que nos salva y cómo conseguirlo; siempre por caminos de mayor complejidad técnica, de tal manera que, a problemas creados por la técnica, será la técnica la única que pueda encontrar la solución. La reflexión del profesor Sanmartín está hecha desde el ámbito de la filosofía de la ciencia, pero tiene evidentes coincidencias con las de nuestro autor.

35 Marcel, Los hombres contra lo humano, 56. 
en los que el fin se convierte en medio, y el medio, en fin. Una realidad de envilecimiento desde la técnica en nuestras sociedades actuales es la utilización de los big data extraídos de las cuentas de redes sociales en las campañas políticas. Se estudian perfiles precisos de posibles votantes y los mensajes que se le hacen llegar son los que quieren escuchar y de la manera que quieren escuchar. Sin apelar a un debate público y abierto donde las razones muevan la decisión, se intenta llegar a los sentimientos y las impresiones más básicas en un proceso que fracciona la sociedad pública en vez de hacerla consistente y en el que los grupos políticos dicen a cada votante lo que quiere oír. ${ }^{36}$

Marcel llama a este sacrificio de la humanidad en el altar de la técnica: envilecimiento de la noción de vida: "Lo que está envilecido es la noción misma de vida, y lo demás viene por añadidura" ${ }^{37}$ La tecnología lo coloniza todo y se arroga el derecho de intervenir en la vida de las personas como se canaliza un río. La psicología conductista y la psicoanalítica entienden la conciencia personal como un engranaje, como una fuerza ciega en los mecanismos o procesos en los que consiste la persona. Anticipando la comprensión fenomenológica de la realidad radical como Vida que propondrá Michel Henry, Marcel señala a través de él la profundidad a que todo dinamismo de la realidad apunta. La Vida no es mera vida biológica, ni siquiera mera vida con capacidades humanas, entendidas estas como capacidades racionales y volitivas, sino que se perfila desde un horizonte de profundidad manifestado en su disminución y reducción:"La experiencia parece revelarnos que, a partir del momento en el que el afán de seguridad domina la vida, esta tiende a reducirse, a replegarse y acurrucarse en sí misma; en suma, a desvitalizarse". ${ }^{38}$ Cuando la persona abandona el horizonte de"ponerse a disposición de la vida" para simplemente "vivir su vida", se ha perdido la profundidad de la existencia, y esto ocurre, "en la medida en que afirma el primado de la técnica y de la inteligencia técnica". ${ }^{39}$ Marcel parece apuntar al concepto de Vida que busca aquilatar Michel Henry en toda su obra; una Vida que es impulso y dinamismo encarnado y trascendente; una Vida que desborda todas las categorías estáticas con las que la ciencia y la

36 El uso de los big data en campañas políticas de diversos países está documentado y comprobada su eficacia técnica de manipulación. Las campañas electorales de Obama, Trump y la del Brexit han mostrado su eficacia (cf. Genma Galdon ClavelL, "Los partidos quieren tus datos", El País. El periódico global, 2019; https://elpais. com/elpais/2019/03/22/ideas/1553277431_155614.html [consulta 17 de septiembre de 2020]).

37 MARCEL, Los hombres contra lo humano, 55.

38 MARCEL, Los hombres contra lo humano, 54.

39 MARCEL, Los hombres contra lo humano, 125. 
técnica se acercan a ella; una Vida que se hace presente en cada viviente y que lo lleva a salir de sí mismo en un dinamismo auto-trascendente y oblativo. $^{40}$

Junto a la enajenación de la conciencia, Marcel señala otro proceso que desencadena la técnica y que lleva también a la desvitalización y la despersonalización: el espejismo de autosuficiencia que trae consigo la tecnología. La técnica nos crea la ilusión de no depender de otra cosa que no sea la técnica que cada día nos"salva" y cada día nos hace la vida más agradable. Recaemos, así, en una ideología de desvinculación egolátrica:"Creemos verdaderamente tan solo en aquello de lo que dependemos; ahora bien, depender de un ser es mantener con ese ser vínculos vitales; el hombre que nada cree, el hombre que no depende de nada, es, al pie de la letra, el hombre sin vínculos. (...) ¿Qué es el tejido de un hombre que ya no cree en nada? ¿A qué le presta atención ese hombre? Lo diré con crudeza: a sí mismo". ${ }^{41}$

La persona configurada unilateralmente por una cultura tecnológica es superficial, inconsciente y ególatra; genera "un mundo en el que los valores universales son sistemáticamente pisoteados" ${ }^{\prime \prime}{ }^{42}$ porque se ha perdido el valor, la dignidad y la trascendencia de la persona. Siendo todo esto causa de una sociedad tecnológica, también es verdad que el oscurecimiento de la dignidad de la persona y de sus valores morales han sido condición de posibilidad para que la ideología tecnológica se adueñara de nuestra sociedad. Por eso, puede decir Marcel que el nihilismo tiene una gran responsabilidad en esta situación de destrucción de lo humano; incluso le"parece totalmente imposible negarle a Nietzsche una responsabilidad al menos indirecta en los horrores cuyos testigos hemos sido y aún somos". ${ }^{43}$ Un nihilismo que desemboca en el poder de lo instintivo, donde el sometimiento del otro o el ser sometido al otro es la clave de la ética, "la moral de los señores y la moral de los esclavos", no podía sino degradarse e ir dando lugar a las peores aberraciones.

\section{RECUPERAR LA CATEGORÍA DE VERDAD Y LA DIMENSIÓN DE TRASCENDENCIA}

El análisis de la técnica ya es una manera de señalar indirectamente caminos de salida ante el laberinto en el que la persona pierde su humanidad y margina su dignidad personal. Pero en la reflexión de Marcel hay intuiciones directas para reconducir los procesos de envilecimiento que

\footnotetext{
40 Cf. Michel Henry, Encarnación: una filosofía de la carne. Salamanca, Sígueme, 2001.

41 MARCEL, Los hombres contra lo humano, 57, 58.

42 MARCEL, Los hombres contra lo humano, 59.

43 MARCEL, Los hombres contra lo humano, 59.
} 
conlleva la tecnología. Uno de ellos es recuperar la categoría de verdad y la dimensión de trascendencia, y el otro redefinir el concepto de progreso y abrirlo al dinamismo de la esperanza. Estas intuiciones están presentes también en otros momentos de su propuesta filosófica.

Recuperar la categoría de verdad y la honradez intelectual a la hora de analizar y valorar la realidad va al centro mismo de las técnicas de cosificación del otro. Comprender al otro en su verdad y comprendernos a nosotros mismos en nuestra verdad, completa y dinámica, son los mejores antídotos ante el envilecimiento de la técnica. Cuando la pretensión de verdad se relega ante otros intereses prácticos estamos ante el precipicio de la cosificación del otro y avanzando a él por el camino de envilecerlo. Toda filosofía que mire con afecto al relativismo, o que confunda la humildad intelectual con un pensamiento débil, acaba renunciando a defender lo verdaderamente humano de la persona. ¿Qué crítica pudo plantear el llamado pensamiento débil ante los fuertes intereses del capitalismo especulativo?

Un ejemplo lo tenemos en una de las redes sociales más importantes: Facebook. En fechas recientes se ha producido una reacción importante a las campañas de odio y difusión masiva de bulos y mentiras contra diversos colectivos o agentes políticos. El enorme poder que ejercen las grandes plataformas tecnológicas de las redes sociales y cómo lo gestionan, se ha puesto en el centro de la crítica. Muchas compañías importantes retiraron su publicidad de Facebook por la dinámica de polarización, violencia verbal y mentiras que ha tolerado. La polarización política y los bulos que se hacen virales son beneficiosos para sus intereses económicos; esos contenidos se hacen fácilmente virales; y cuanto más tráfico de mensajes, reenvíos y respuestas airadas, mayores son los ingresos publicitarios. ${ }^{44}$ Estas campañas de bulos y polarización no son, la mayor parte de las veces, espontáneas, sino que están diseñadas al servicio de la propaganda política; una propaganda que se entiende como técnica de envilecimiento.

El análisis puede tener un mayor alcance. No sólo las campañas criminalizadoras del adversario envilecen; aunque no tenga ese objetivo, la propaganda siempre tiende a cosificar a su destinatario. No apela a la razón y a la verdad para hacer crecer a la persona, sino a instancias inconscientes o a la mentira para manipularlo. El objetivo de la propaganda es siempre "envilecer a aquellos sobre quienes se ejerce y que, por añadidura, supone un hondo desprecio hacia ellos. Toda propaganda implica,

44 Editorial de"El País", 2 de julio el 2020, (https://elpais.com/opinion/2020-07-01/facebook-y-el-odio.html; consulta 4 de julio del 2020). 
en suma, la pretensión de manipular las conciencias. (...) La propaganda es el desconocimiento cínico de esa ordenación de las conciencias a la verdad" ${ }^{45}$ Sin el horizonte de la verdad, nada en la persona puede ser verdaderamente humano. Una verdad que busca universalidad. Cuando en nombre de la clase, la cultura o la raza se ha repudiado la verdad que se define en el horizonte de lo universal, siempre se ha recalado en la irracionalidad despersonalizadora y criminal.

Marcel va más allá y reconoce que él mismo, en algunos momentos de su vida, pensó que las categorías de compromiso o apuesta vital podían desplazar a la categoría verdad para estructurar la persona. Reconoce su error. Esta reflexión sobre el envilecimiento de la técnica es una advertencia grave y solemne "a los que pretenden sustituir las categorías tradicionales que se organizan en torno a la noción de verdad por las categorías trágicas como las de compromiso, apuesta, riesgo" ${ }^{46}$ Quizás con buena intención, pero también se acaba degradando a las personas en un pragmatismo miope que diluye su dignidad intrínseca. Sin el horizonte de la verdad, ni la solidaridad, ni la creatividad, ni la misma existencia pueden ser verdaderamente humanas.

Pareciera que Marcel estuviera contemplando los debates políticos de nuestros medios de comunicación, donde importa más quién habla más fuerte y con más rotundidad, que los argumentos y los datos que se aportan: "El prodigioso envilecimiento de la discusión, de las mismas bases de la discusión, del que cada día nos aporta los más desoladores testimonios. (...) Todo muestra que el sentido de los matices, inseparable del sentido de la verdad, está literalmente asfixiado por las pasiones sectarias". ${ }^{47}$

Esta verdad en la que hemos de configurar nuestra vida se define en el horizonte de nuestra realidad de criaturas, de seres dependientes y limitados. Un dato radicalmente importante en el horizonte de la verdad en el que hemos de constituirnos las personas es el reconocimiento de nuestra finitud y de que todo lo que somos y tenemos es, en su última raíz, don. Es decir, que nuestra verdad se descubre en el horizonte de la creación. Cuando se abandona este horizonte, la persona abandona su realidad y tiene que elaborar mentiras que lo hacen dueño y señor de todo o un mero constructo fortuito de las causas y los azares de la naturaleza. A partir del momento en que el propio hombre niega esto le acecha un doble peligro:

\footnotetext{
45 MARCEL, Los hombres contra lo humano, 61.

46 MARCEL, Los hombres contra lo humano, 61.

47 Marcel, Los hombres contra lo humano, 63.
} 
Por un lado, se verá arrastrado - y esto es exactamente lo que constatamos en el existencialismo de Sartre- a otorgarse a sí mismo una especie de aseidad caricaturesca, es decir, a considerarse como un ser que se hace a sí mismo y que no es sino lo que se hace; puesto que no existe nadie que pueda colmarlo, no existe siquiera un don que pueda serle hecho; un ser tal se presenta como profundamente incapaz de recibir. Pero, desde otro punto de vista, y ligado a ello, el hombre se verá igualmente arrastrado a considerarse como una especie de desecho de un cosmos por añadidura impensable como tal — de suerte que le veremos, a la vez y por las mismas razones, exaltarse y despreciarse desmesuradamente-. ${ }^{48}$

En un mundo centrado en la idea de función, la vida deja de tener sentido alguno porque el mundo está vacío. Sin lugar para el misterio la persona queda reducida a un objeto más entre los objetos, y sus decisiones dejan de tener algún valor más allá de sí mismas. Incluso en los escasos momentos en los que pudiéramos sentirnos creadores de nosotros mismos, artífices"ex nihilo" de nuestra realidad, esa misma creación acabaría engullida por el decurso de la historia. El amor, el sentido de la vida, el bien, la libertad dejan de tener sentido con la categoría pseudocientífica de lo "enteramente natural". Nada hay en la persona"enteramente natural porque somos seres personales. Ese misterio que cifra nuestra vida se pone de manifiesto en acontecimientos como el nacimiento, el amor, la muerte, etc.; acontecimientos que dejan nuestro espíritu entre el milagro y el asombro. ${ }^{49}$

\section{ESPERANZA VERSUS TECNOCRACIA: LAS REDES SOCIALES}

Como se ha apuntado anteriormente, todo desarrollo técnico nace de nuestra razón como actualización de la verdad de lo real y de nuestro deseo de vivir con plenitud. Nace de la búsqueda de la razón y del anhelo del deseo. La técnica brota del corazón mismo de la esperanza humana. Y, de hecho, la tecnología busca responder a las necesidades y deseos que en cada momento de la historia tiene la humanidad. Por eso, la técnica, cuando nace del afán por mejorar la vida de los otros, por aliviar sus dificultades, para ayudarles a superar sus limitaciones, desarrolla nuestro propio espíritu; podría decirse que se vive en "la verdadera esperanza que nos une a un cierto orden espiritual en el cual mi existencia conserva sentido y valor" ${ }^{50}$ Pero nuestros deseos no siempre responden a

48 MARCEL, Los hombres contra lo humano, 60.

49 Cf. Gabriel Marcel, Aproximación al misterio del ser. Madrid, Encuentro, 1987, 29.

50 Gabriel MArcel, Homo Viator. Prolegómenos a una metafísica de la esperanza, Salamanca, Sígueme, Salamanca 2005, 60. 
los anhelos que nos humanizan y nos permiten realizar lo que somos. Cuando las expectativas que genera el desarrollo tecnológico se desvinculan de las esperanzas reales y de la verdadera humanidad, degeneran en tecnocracia. El dinamismo de la esperanza desaparece y solo queda el proceso de cosificación de la naturaleza, del otro y de mi propio ser, guiado por un impulso ciego con apariencia de racionalidad.

Eso es precisamente lo que denuncia un documental protagonizado por un número significativo de exempleados de alto rango de importantes empresas de redes sociales. ${ }^{51}$ En él van desgranando los diversos procesos de manipulación y de envilecimiento que provocan las redes en las personas individuales y en el conjunto de la sociedad.

El primero de los procesos perniciosos de las redes sociales, denunciado en el documental, es la capacidad de acaparar tiempo e interés que tienen; es decir, su poder adictivo, que aleja a quienes se involucran en ellas de la vida cotidiana, de las relaciones personales verdaderas. Están diseñadas para que no haya lugar para retirarse sin esfuerzo y sin renunciar a ver algo que ya está iniciándose en la pantalla: la reproducción continua de vídeos, las llamadas a conectarte en cuando alguien te"etiqueta" en alguna foto, las llamadas de atención diarias si no te conectas, etc. La pretensión y la capacidad adictiva de las redes es palpable en nuestro mundo. Una capacidad adictiva que elimina toda posibilidad de creación, nos reduce a ser seres necesitantes de un producto. Lo que llama a nuestra creatividad nunca nos esclaviza, ni nos reduce a ser números de una masa. Conforme una persona es atrapada en una adicción y deja de ser creativo pierde realidad personal, pierde su propia y única realidad, como nos señalaba Marcel en los inicios de este análisis. A las redes sociales se les sacrifica todo: el tiempo, el sueño, las relaciones humanas, incluidas las sexuales, nuestra propia intimidad. Se han convertido en cierto aspecto para nosotros en verdaderos ídolos a los que les sacrificamos nuestra propia humanidad.

Otro proceso negativo, sobre todo en los adolescentes y en adultos inmaduros, es la necesidad de crear un perfil icónico atractivo y sugerente de uno mismo, basado en fotos y en los eventos que se comparten.

51 "El dilema de las redes sociales", producido por Jeff OrLOWski y comercializado en la plataforma Neflix. En él intervienen: Tristan HarRis, exdiseñador ético de Google; Aza Raskin, el cofundador de Asana; Justin Rosenstein, extrabajador de Facebook y cocreador del botón de Me Gusta de dicha plataforma; el presidente de Pinterest, Tim Kendall; el director de política de investigación de IA Now, Rashida Richardson; el director de investigación de Yonder, Renee DiRESTA; el director de programa de la Sociedad Médica de Adicciones de la Universidad de Stanford Anna LembKe, y el pionero de realidad virtual Jaron LANIER. 
Estos perfiles son normalmente ficticios, porque solo vemos lo que los demás hacen de extraordinario, cuando nuestra vida es ordinariamente muy ordinaria. Esta situación genera una frustración que puede estar presente como una de las causas en el aumento tan significativo de adolescentes que se suicidan o intentan suicidarse. A fuerza de vivir en la superficie quedamos huecos y vacíos, como apuntaba Camús del dios Jano, quien, mirando con su doble rostro a todos lados sin concentrarse en ninguno, solo tenía vacío en su interior.

Especialmente significativa es la hipótesis que propone el documental de cómo las redes sociales influyen en la imagen del mundo que tenemos, y cómo desencadenan dos procesos muy perniciosos en la manera que tenemos de comprender nuestra realidad social. En primer lugar, como las aplicaciones buscan lo que a cada usuario puede interesarle más, le ofrecen solo las informaciones y los productos audiovisuales, coherentes con su historial de búsquedas. De tal manera que dos personas que viven una misma realidad social pueden no compartir en absoluto la realidad virtual que viven. Hasta llegar a tener una imagen del mundo completamente distinta, no por decisión y reflexión personal, sino de manera inconsciente y no voluntaria, por la selección de información que hacen para su perfil de usuario cada red social.Vivimos, por tanto, una situación en la que no hay una percepción compartida o común del mundo; cada uno ve el mundo siempre desde lo que ha manifestado como sus intereses, estrechándose las experiencias que nos ofrecen y reiterándose de manera machacona. Si, por ejemplo, mostramos interés por un tipo de música, los otros tipos de música van desapareciendo de la oferta que vemos en nuestra pantalla. La personalización de la oferta va a lo seguro y eso estrecha nuestro horizonte en las redes. Esto que ocurre con la música, también ocurre con análisis políticos, o con los problemas sociales que aparecen en el universo de nuestra pantalla. En vez de compartir un mundo en el que cada uno tiene su propia opinión de las mismas cosas, las nuevas tecnologías hacen que cada uno tenga su mundo donde es posible que las realidades que preocupan o interesan a los demás simplemente no existen, o se hacen incomprensibles y absurdas. Cada uno de nosotros, cada grupo de población definido por un perfil concreto, va viviendo una realidad sesgada, una pseudo-realidad como la que hacen vivir los regímenes totalitarios, como nos recordaba Hannah Arendt. La consecuencia última es que la cohesión de nuestras sociedades está siendo minada desde su propia base.

En segundo lugar, hay otra tendencia que está presente en todo proceso de comunicación, y que en las redes sociales multiplica su peso: siempre lo más extremo, lo más radical, lo más extravagante llama más 
la atención, y en las redes sociales es lo más curioseado, lo más visto, lo más reproducido y compartido; de tal manera que la reducción de nuestro mundo mediático, que antes mencionábamos, se hace con una fuerte tendencia a los extremos. Quien se informa de lo que ocurre en el mundo por las redes sociales se ve sometido a una constante tensión a la polarización y al extremismo. Por eso —argumenta el documental— los procesos de las redes están minando la cohesión social y la conciencia de las diversas sociedades de luchar por un destino común. Eso, vaticinan, pondrá en peligro la paz y la democracia en un periodo relativamente corto de tiempo.

La causa de todo esto no es una opción moral de los dueños de las distintas redes sociales, por lo menos en un primer momento. El agente directo es el algoritmo que controla nuestras búsquedas y nuestro historial de conectividad; que nos ofrece lo que predice que va a captar nuestra atención. Es un algoritmo diseñado para que consumamos tiempo en las redes, para absorber nuestra atención y nuestro interés; ese es el negocio de las redes. Los clientes de las redes sociales son sus anunciantes; ellos son los que ponen dinero y compran participaciones de las distintas aplicaciones. Para nosotros, esas aplicaciones son gratuitas, los usuarios no ponemos dinero, por lo que no somos ni vendedores ni clientes; nosotros somos el producto que se negocia. Son nuestro tiempo, nuestra imagen del mundo, nuestros deseos lo que se comercia en las redes sociales; esto le da orientación y sentido a su actividad: nuestro tiempo y nuestros deseos son su producto. Este algoritmo es el sujeto impersonal de la técnica del que hablábamos al principio del artículo y que convierte en objeto a las personas, negando desde procesos reales su dignidad y el misterio de su ser.

Siempre la actividad comercial ha intentado llamar nuestra atención y suscitar nuestros deseos; la publicidad en los medios de comunicación siempre ha tenido influencia en las personas, ese era también su negocio; pero en las redes sociales hay un ejército de publicistas que utilizan todas sus armas para captar la atención y exacerbar los deseos de cada persona concreta.Y esto es la primera vez que ocurre en la historia.

Todos estos procesos son conscientemente aprovechados por las empresas digitales. Sus empleados saben que su negocio tiene una vertiente profundamente negativa para las personas y la sociedad, para sus propios hijos; pero ese es su trabajo. Su trabajo tecnológico tiene la consecuencia directa de envilecer a las personas y a la sociedad. Los participantes en este documental se hicieron conscientes de ese hecho y de cómo ellos mismos estaban envileciéndose, colaborando con el envilecimiento de la sociedad. Para romper ese círculo vicioso tomaron la decisión de hacernos conscientes de la fragilidad del ser humano ante el 
dominio de las redes, y, desde ese hecho, reivindicar una regulación de las mismas.

Los análisis de Marcel se muestran en este tema clarividentes. Cuando se expulsa la dimensión espiritual de las personas del uso de la tecnología, cuando quien usa la técnica no lo hace integrando su propia creatividad, se deshumaniza, se envilece. La tecnología que apela a los impulsos más básicos y simples de nuestra realidad, a nuestro "cerebro de lagarto" — como dice Tristan Harris—, en vez de a nuestro "cerebro reflexivo", genera adicción y adocenamiento; en definitiva, envilece a las personas. ${ }^{52}$ Solo cuando la tecnología integra y potencia nuestro"cerebro espiritual" se redime a sí misma.

Cuando las inquietudes y los intereses de las personas se cosifican, se termina instrumentalizando a todos los que las rodean. Cuando el objetivo de la tecnología se reduce a acumulación de bienes materiales, a eficiencia material, al crecimiento productivo o financiero, se agota en la reiteración de lo mismo, no aporta verdadero crecimiento en humanidad. Una técnica así ni brota de la búsqueda y el anhelo de la esperanza, ni puede suscitarla; la utopía se convierte en distopía, los sueños en pesadillas. Creíamos que las redes sociales podían ser una ayuda para solucionar muchos problemas y nos hemos dado cuenta de que tienen la cara oculta de atraer en nuestra vida "distracción, encierro y soledad; nos hemos empachado de conexiones y hemos perdido el sabor de la fraternidad". ${ }^{53}$

La tecnología, para no caer en la maldición de Ícaro, ha de situarse no en el horizonte de la acumulación, sino en el de la donación, en el de la entrega y en el del compartir. Sin el horizonte del otro, nada hay verdaderamente humano. No hay esperanza verdadera sin amor, en el puro egoísmo. Marcel señala una expresión que pretende adentrarse en el dinamismo común de la esperanza:" "Yo espero en ti para nosotros». Tú eres, en alguna manera, el garante de esta unidad que me liga a mí mismo". ${ }^{54}$ Nuestra sociedad tiene el reto de hacer que el desarrollo tecnológico actual, que como hemos visto va muchas veces contra la humanidad de la persona, se ponga al servicio de alentar la esperanza.

52 Tristan HARRIS, Conferencia Ted 2017. Ideas Worth Spreading: https://www.ted.com/ talks/tristan_harris_how_a_handful_of_tech_companies_control_billions_of_ minds_every_day?language=es (consulta 30 de septiembre de 2020).

53 Papa Francisco, Carta Encíclica "Fratelli Tutti". Sobre la fraternidad y la amistad social, n. 33.

54 Marcel, Homo Viator, 72. 
